\title{
Research of Employee Retention on Job Embeddedness Perspective
}

\author{
Yan Zhang ${ }^{1}$ \\ ${ }^{1}$ College of Business, Hohai University, Nanjing 211100, China
}

\begin{abstract}
Employee turnover will bring high cost to organization and individuals. In organization, the most prominent problem is to attract and retain valuable employees. This paper breaks through the traditional model, introduces the job embeddedness theory, and explore the influence factors of employee retention. Finally, it gives feasible improvement plan and suggestion from the job embeddedness perspective combined with the four force model. It is expected to be able to retain a large number of outstanding talents and lay a solid foundation for the development of enterprises through the suggestions.
\end{abstract}

Keywords: job embeddedness; employee retention; employee dimission; turnover; four force model

\section{Introduction}

Employee turnover will bring high cost, it is not conducive to the development of the enterprise. For the enterprise, employee turnover means to recruite, select and traine the new employees, which will cost a lot of manpower, material resources, financial resources and time. What's more, it will affect the production efficiency and bring about loss of human capital and social capital.

\section{Traditional Model}

Over the past half century, March and Simon model has been the tranditional model to explain employee employee turnover based on the perceived ease and desirability of leaving one's job. The trandional model considers that people become dissatisfied with their jobs, search for alternatives, compare those options with their current jobs, and leave if the alternatives are judged to be better than their current jobs. In the trandinal model, job attitude is regarded as the cause and core variable to turnover. While the follow researchers have found that although the links among job attitude, perceived alternative, search, and turnover are consistent, the impact on the turnover is not significant as expect. For example, Hom and Griffeth found that attitude variables control only 4 to 5 percent of the variance in turnover. So, many other meaningful topics may have been neglected.

\section{Job Embeddedness}

Mitchell, a professor of Washington University, found that many employees leaving the company are not depending on their attitudes or job alternatives, but on the "shock", such as the enterprise merger, friends leaving, further studying, the birth of children and relative's work change. These "shocks" have no necessary connection with job attitude, but they have an important effect on employee turnover. Therefore, in order to better explain the phenomenon of employee turnover, Mitchell and Lee put forward job embeddedness therory based on "non-work factors", "field theory" and "unfold model". It represents a broad set of influences on an employee's decision to stay on the job. These influences include on-the-job factors and off-the-job factors. Speaking briefly, job embeddedness is focused on how the interanl and external enviromenta of job affect employee turnover. It is like a net or a web in which an individual can becomen stuck. One who is highly embedded will be easily affected by the network relationships in different level.

The critical aspects of job embeddedness are the extent to which people have links to other people or activities, the extent to which their jobs and communities are similar to or fit with the other aspects in their life spaces, and the ease with which what they would give up if they left. These dimensions are called fit ,links and sacrifice, and they are important both on and off the job. It suggests six dimensions of job 
embeddedness: organization links, organization fit, organization sacrifice, community links, community fit and community sacrifice.

\subsection{Links}

Links describes the formal or informal connections in organization or in community. Job embeddedness theory points out that the individual life is constituted of a number of network connecting an employee and his or her family in a social,psychological, and financial web that includes work and nonwork friends, groups, the community, and the physical environment. Employee relationship with superiors and the relationship between staff and team form the links between employee and organization, whlie the employee connection with neighborhood, colleagues, relatives or friends in the same community make up the links between employee and community. The higher the number of links between the employee and the network, the greater the emplyee embedded in his work. A large number of studies have shown that links from working partners, colleagues, family, relatives and companies will enhance the staffs' attachment and encourage them to keep the retention.

\subsection{Fit}

Mitchell consider the fit is referred to "the compatibility employees perceived from the enterprise and the community, and they will not adapt to the new situation once they leave the enterprise or the community". According to the theory, the most important fit is that an employee's interest, career goals and personal value should be consistent with the organization culture and the demands of his or her immediate job. Similarly, employees will also consider the factors affecting the matching degree between the community and the surrounding environment, such as community climate, entertainment facilities, customs, policy and belief, in which the evaluation have no association with the enterprise or work. Studies have shown that the better the fit with the organization and the community, the higher the likelihood that an employee will stay in the organization.

\subsection{Sacrifice}

Sacrifice represents the perceived cost of material or psychological benefits that are forfeited by organizational departure. The cost is related with the job loss and the community loss. Job loss mainly refers to that employees will have to give up the interesting items, the colleagues getting along with in long-term, promotion opportunities, job security and other non-economic benefits. And they will alos lose the economic benefits such as the stock options, retirement compensation plans and so on. At the same time, with the departure, it will lead to the instability of the future work and unstable income. The community losses mainly mean that employees have to move out the secure and familiar community, say goodbye to the friendly neighbors and leave the comfortable life environment. The more an employee will have to give up when leaving, the more difficult it will be to sever employment with the organization. Similarly, leaving a community that is attractive and safe can be difficult for employees.

\section{Retention Suggestion}

The three professor of Harvard business school, Nitin Nohria, Boris Groysberg and Linda reveals that human behavior is decided by four kinds of emotional driving force: combination, comprehension, acquisition and defense. Combination is to establish connection with individuals and groups; Comprehension is to satisfy the curiosity and understand the world around; Acquisition means to get scarce thing including the intangible things such as social status; Defense is to protect self from external threats and promote justice. They thought the driving force is the foundation of all human behavior, which is the root of the employees working behavior in organizations. And the appearance of the emotional driving force has pointed the way for us to study further on how to improve employee retention situation. So we'll give the retention suggestion combining with the emotional driving force from the job embeddedness perspective.

\subsection{Combine with Organization culture to Establish Close Links}

Within the concept of combination, many kinds of animals have establish close relationship with their relatives or population, but only humans have extended the relationship to a larger groups, such as organization, community or nation. As in the work environment, 
when employees are proud of theirselves as a member of the organization, or think they are the indispensable members of the organization, their willingness to work will be greatly improved. Therefore, the best way to establish the links between employees and enterprises is to make employees have a sense of belonging to the enterprise and to meet the needs of employees' combination emotional driving force. So the most effective way is to establish a kind of culture that can promote teamwork, collaboration, openness and friendship. It should be improved from the employees' career planning to ehance the links between employee and enterprise. Based on the research, analysis and summarize of the subjective and objective factors of a person's career, we can make a comprehensive evaluate about their interest, ability, specialty, experience and insufficient combining with the characteristics of era. So the organization should determine the best career goals according to its professional tendency and make effective arrangements to achieve this goal. With the above measures, the links between enterprises and employees will be greatly enhanced.

\subsection{Ehance the Comprehension of Job Fit}

People are eager to know the world and put forward various theories to explain all sorts of things from scientific, religious, and cultural aspects. And they put forward reasonable actions and responses. Whlie employees hope that the organization can understand their pursuit and provide effective help for them. Therefore, it will be able to effectively improve the fit between the staff and the enterprises from the comprehension driving force. And the best way to meet the comprehension driving force is to design a meaningful, fun and challenging jobs. Firstly, understanding the development demand of employees. Only understanding and paying attention to the employee's development needs, guiding their interests and creating favorable environment for their growth can it stimulate staff's work enthusiasm and enhance organizational attractiveness. So job design should be in line with the workers features. Secondly, designing jobs combining with organizational development strategy. Job design should meet the development demand of people and also undertake its responsibility to complete the organizational goals, which is consistent with the requirement of enterprise development strategy. Thirdly, providing job training for employees. Effective training is not only through the content, but also through the vivid expression training. It can renewal employees' knowledge and skills and make the employees have the ability to competent for challenging jobs. So reasonable job design can make the staff and enterprise both have a new understanding to the position, improve the fit between them and retain the talents at last.

\subsection{Aggravate Departure Sacrifice through Abundant Acquisition}

Acquisition means everyone will try to get what they want in order to improve their well-being. The more employees acquire in the enterprise, the more they will sacrifice when leaving. So we can combine the incentives and sacrifice dimension, which means give employees more and ehance the difficulties when they want to give up. We can use reward mechanism from the material and spiritual double aspects to strengthen employees job embeddedness. On the material reward, it can give certain bonuses based on employee's performance. And the bonuses can be adjusted according to the employees' suggestions and supplement. The enterprise should make rewards as a guidance goal to arouse employees' enthusiasm and creativity. Similarly, it can not be ignored about the spiritual compensation, of which effects tend to outweigh the material rewards. For the spiritual compensation, we can provide promotion opportunity for the outstanding employee, provide the training learning opportunities and make the written or verbal praise for theri outstanding contributions.

\subsection{Defense External Threat}

Defense is to find the method to establish a series of system to promote justice, confirm objectives, create a safe environment and gain the trust between each other. Defense is the most comprehensive emotional driving force to job embeddedness, which eliminates the various hidden dangers and threats and promote the relationship between individuals and enterprises. It also reassure employees to stuck in enterprise network. Decision-making of process and optimization of management environmental can effectively meet the defense emotional driving force. First, establishing fair and open internal process including transparent of 
appraisal process, justice of employee selection and appointment, and reasonable rewards and punishment system. Only through the fair and open internal process can it establish the employee trust on organization and intention to stay inthe organization. Second, establishing the trust between superior and subordinate. Superior should support to subordinate work and provide comprehensive equipment or conditions as far as possible. They can also authorize their subordinate according to the organization's goals and tasks and increase employees' job autonomy and responsibility. Third, establishing a stable work environment. The stability of the work is also an important factors that affect employee turnover rate, many employees like family atmosphere and don't want the change of their work environment or colleagues. Therefore, organization can establish healthy and lively cultural life environment, conduct some significant cultural activities and improve employee benefits to make employee feel the warmth and harmony of family.

\section{Conclusion}

Nowadays, life is becoming more and more complex, in order to simplify life and avoid many contradictions, employees will work efficiently to get more. And if they feel their own value have been recognized by the organization, they are inclined to stay in the original. Job embeddedness seize these key theory, start from the enterprise and the community two aspects, and explore the reasons of employee retention. At the same time, in order to effectively implement the retention plan, different companies need staffs with different knowledge, skills, and ability. So, there is not a general retention plan, every company should set the plan from themselves according to their own actual situation and make corresponding retention plan. The paper gives a feasible improvement plan and suggestion combined with four force model from job embeddedness perspective. It will firmly retain a large number of outstanding talents and reduce staff turnover, which will lay a solid foundation for the development of enterprises. Only in this way, a large number of surplus manpower capital can promote enterprise social capital.

\section{References}

[1] Glebbeek, A. C., \& Bax, E. H. (2004). Is high employee turnover really harmful? An empirical test using company records. Academy of Management Journal, 47, 277-286.

[2] Becker, Brian E., Huselid, Mark A., \& Ulrich, D. 2001. The HR Scorecard: Linking people, strategy, and performance. Boston: Harvard Business School Press.

[3] Fishman, C. (1998, August). War for talent. Fast Company, pp. 104-106.

[4] March, J. G., Simon, H. A.. Organizations, New York: Wiley, 1958.

[5] Hom, P. W., \& Griffeth, R. W. (1995). Employee turnover. Cincinnati, OH: South-Western College Publishing.

[6] Mobley, W.H. 1982. Employee turnover, causes, consequences, and control. Reading, MA: Addison-Wesley.

[7] Nitin Nohria, Boris Groysberg, and Linda-Eling Lee. Employee Motivation: A Powerful New Model. Harvard Business Review, 2008(7). 